\title{
EDITORIAL
}

\section{Importancia de la investigación cualitativa para la Enfermería}

L

a profesión de enfermería es una de las profesiones que trabaja de cerca y de lleno con el ser humano en todas las etapas de su vida, incluso en el proceso de muerte, tiene el gran privilegio de verlo y cuidarlo durante el nacimiento y en el acto de muerte, proporcionar el cuidado en los diferentes espacios en los que convive el ser humano como los hospitales, el domicilio, las empresas, por mencionar algunos. Esta característica, muy propia de enfermería le permite que tenga la capacidad de realizar diferentes funciones como la docencia, la gestión, el cuidado y la investigación.

La investigación es una actividad que se ha ido construyendo paso a paso, comenzó a desarrollarse desde el mismo momento de la creación de la profesión por Florencia Nightingale, durante el siglo XX existen toda una serie de investigaciones realizadas por enfermeras (ros) en el ámbito cuantitativo, sin embargo es a finales de este siglo e inicios del siglo XXI cuando empieza a incursionar con la investigación cualitativa.

"La investigación cualitativa es un campo interdisciplinar, transdisciplinar y en ocasiones contradisciplinar. Atraviesa las humanidades, las ciencias sociales y las físicas. La investigación cualitativa es muchas cosas al mismo tiempo. Es multiparadigmática en su enfoque. Los que la practican son sensibles al valor del enfoque multimetódico"

La investigación cualitativa es una de las mejores compañeras con las que puede trabajar enfermería, la une el ser humano, una de las habilidades de la enfermería es su capacidad de comunicación con el ser humano, independientemente de la etapa que viva, realizar y aplicar la investigación cualitativa le permite conocer sus diferentes facetas, etapas, momentos, significados, emociones para mejorar el cuidado que le proporciona debido a que este tipo de investigación tiene una "tendencia definida, de naturaleza desreificadora de los fenómenos, del conocimiento y del ser humano"

El aplicar este tipo de investigación le da mayor fuerza a la profesión de enfermería a partir de que siempre ha considerado que el ser humano es único, le permite conocerlo en sus particularidades para proporcionar un cuidado holístico, pero sobre todo le da la oportunidad de transformar su propio ser y hacer, dado que la investigación cualitativa tiene diferentes metodologías para acercarse al objeto de estudio, porque entiende que el conocimiento no es acabado sino que se construye y reconstruye dentro de la complejidad de la sociedad en que vivimos, en donde el hombre siempre está en la búsqueda de su bienestar independientemente de que este sano o enfermo, enfermería siempre está ahí acompañándolo, guiándolo y cuidándolo.

\author{
Dra. María del Pilar Sosa-Rosas \\ Doctora en Ciencias de Enfermería \\ Profesor Titular "B" Tiempo Completo \\ Miembro del Sistema Nacional de Investigadores (SNI I) \\ Escuela Nacional de Enfermería y Obstetricia \\ Universidad Nacional Autónoma de México \\ soosa99@yahoo.com
}

\section{REFERENCIAS BIBLIOGRÁFICAS}

1.Rodríguez G, Gil J, García-Jiménez E. Metodología de la investigación cualitativa. España: Ediciones ALJIBE; 1999.378 p.

2.Silva A. Introducción a la investigación en ciencias sociales: investigación cualitativa en educación. Brasil: Editorial ATLAS; 1992.125 p. 